\title{
Effectiveness of public health and education programs for creating awareness of and managing cardiovascular disease
}

REVIEW

This article was published in the following Dove Press journal:

Patient Intelligence

I6 February 201 I

Number of times this article has been viewed

\section{Simon White}

School of Pharmacy, Keele University, Keele, Staffordshire, UK
Correspondence: Simon White School of Pharmacy, Keele University, Keele, Staffordshire, ST5 5BG, UK Tel +440 I78 2734772

Email s.j.white@mema.keele.ac.uk
Abstract: This paper reviews the effectiveness of public health and education programs for creating awareness of, preventing and managing cardiovascular disease (CVD), with a particular focus on their impact on people's behavior. Evidence-based guidance recommends that such programs, eg, cardiac rehabilitation, should include risk assessment, modification of lifestyle risk factors and, where appropriate, medication. However, despite substantial evidence of cardiac rehabilitation being beneficial, a significant proportion of eligible patients fail to receive cardiac rehabilitation and numerous barriers to attendance remain, particularly because cardiac rehabilitation service provision continues to be patchy and of variable quality. Evidence suggests that educational programs to prevent CVD may achieve favorable reductions in mortality and overall CVD risk. However, whilst people tend to have significant knowledge of the modifiable risk factors for CVD, this does not necessarily lead to action to reduce risk, because lay epidemiology appears to play a significant role in sophisticated determinations of CVD causation, amongst other factors. Some people, but not all, make and maintain some lifestyle changes, but not necessarily all of the changes recommended, because they may only change aspects of lifestyle that are perceived to have been likely causes of their CVD. In addition, many people experience difficulty in making and maintaining lifestyle changes. There appears to be considerable disquiet among patients about taking medicines prescribed for CVD, particularly concerning side effects, which in some instances may affect medicine-taking. New developments and patient approaches recognize the wider societal issues that influence the lifestyle choices people make. Initiatives to increase attendance and widen access to cardiac rehabilitation have included home-based and technological innovations as alternatives to hospital-based cardiac rehabilitation programs. Effective future approaches are likely to build on these developments, and offer even greater choice in accessing preventative services.

Keywords: cardiovascular disease, public health, education programs, cardiac rehabilitation, lifestyle change

\section{Introduction}

Cardiovascular disease (CVD) remains a leading cause of global morbidity and mortality, particularly in developed countries, although there is wide variation in death rates according to age, gender, socioeconomic status, ethnicity, and geographic location. ${ }^{1,2}$ From a biomedical perspective, CVD can perhaps be best viewed as a continuum of a pathological process, in which the arteries gradually thicken and harden, and atherosclerotic plaques develop that further occlude blood flow. This leads to clinical manifestations, such as coronary heart disease, stroke, and peripheral vascular disease. The World Health Organization reported that in 2005 CVD accounted 
for approximately $30 \%$ of an estimated all-cause total of 58 million deaths globally. ${ }^{2}$ In England, for example, it is estimated that in 2007 approximately 159,000 deaths resulted from CVD, accounting for 34\% of all deaths in England during this period. ${ }^{1}$ Furthermore, the CVD death rate in the UK is three times higher in men aged younger than 75 years than in women, twice as high in socioeconomically disadvantaged areas compared with more affluent areas, and nearly $50 \%$ higher in people of South Asian origin than in the general population. ${ }^{3,4}$ Similar CVD-related health inequalities have been found in other developed countries. ${ }^{1,5,6}$

In response, many countries have introduced health policies that aim to reduce significant causes of CVD-related mortality and morbidity in their populations, which align with the World Health Organization 2007 guidance on CVD prevention. ${ }^{2}$ These include primary prevention strategies to reduce risk factors in the whole population and aimed at people at high risk of developing manifestations of CVD, and secondary prevention strategies aimed at people who already exhibit such manifestations. Population-based approaches aim to reduce the incidence of risk factors for CVD (especially those related to lifestyle) in the whole (low-risk) population in order to reach a small number of high-risk individuals. ${ }^{1,2,7}$ Approaches that target individuals with a high baseline risk do so on the basis of epidemiological evidence indicating that a disproportionately large number of CVD-related deaths $(30 \%-40 \%)$ occur in the small proportion (less than $20 \%$ ) of the population who are deemed to be at high risk. ${ }^{7-9}$ Evidence-based guidance recommends that people at high risk should be prescribed appropriate medication (eg, to reduce their blood pressure and cholesterol) and be advised to meet a series of lifestyle targets. Patients with established CVD are considered to be at high risk, as assessed by algorithms, such as the Joint British Societies 2005 and the World Health Organization's 2007 risk prediction charts. ${ }^{2,10}$ Where eligible, these patients should be offered cardiac rehabilitation, which should offer a comprehensive, integrated, and evidence-based approach to secondary prevention of CVD. ${ }^{4,11,12}$

Evidence-based guidance concerning medication recommends the use of aspirin, beta-blockers, angiotensinconverting enzyme inhibitors, and cholesterol-lowering drugs (eg, statins) for secondary prevention of CVD. ${ }^{2,4,10}$ Lifestyle-related recommendations for both primary and secondary prevention of CVD concern stopping smoking (where relevant), diet, physical exercise, and weight. ${ }^{2,4,10}$ A Mediterranean-style diet is recommended, which includes at least five portions of fresh fruit and vegetables a day, at least two servings of oily fish per week, and minimizing saturated fat intake by replacement with monounsaturated fats. ${ }^{4,10}$ Other dietary recommendations include limiting salt intake to less than $6 \mathrm{~g}$ daily and alcohol intake to less than 2-3 units per day for women and 3-4 units per day for men. ${ }^{13}$ Regular physical exercise is recommended for at least 20-30 minutes per day on most days of the week. $^{4,10}$ In addition, it is recommended that ideal body weight (ie, body mass index, $20-25 \mathrm{~kg} / \mathrm{m}^{2}$ ) be achieved and maintained. ${ }^{10}$

However, although overall CVD-related mortality and morbidity has decreased in most developed countries over the past 10 years, ${ }^{1}$ the evidence continues to suggest that a significant proportion of people do not modify their lifestyles, do not take prescribed CVD-related medicines, and do not attend cardiac rehabilitation programs. ${ }^{1,2,5,14-16}$ As such, the purpose of this paper is to review the effectiveness of public health and education programs for creating awareness of, preventing and managing CVD, with a particular focus on how such programs impact on people's behavior. This begins with a brief review of the history of the programs for CVD and the evidence base for their effectiveness. The paper then considers in detail their impact on people's behavior by discussing public perceptions of CVD risk, patient perspectives on cardiac rehabilitation programs, patient perspectives on taking CVD-related medicines, and patient perspectives on lifestyle modification recommendations. New developments and patient approaches are then discussed, followed by consideration of some potential future developments. In preparing this review, recent guidance, reports, and studies written in the English language from national institutions and other authoritative organizations were drawn on. The sections on patient behavior intentionally focus on dominant themes drawn from the largely qualitative bodies of literature on lay perspectives, because it has not been possible to refer to every relevant published study, given the voluminous nature of the literature.

\section{History and effectiveness of cardiovascular disease education programs}

In the latter half of the last century, accumulating evidence indicated that early activity after a myocardial infarction resulted in better health outcomes than prolonged bed rest. ${ }^{17}$ This led to the development of cardiac rehabilitation programs in developed countries to provide supervised, structured physical activity, initially for postmyocardial infarction inpatients and later for outpatients as well. ${ }^{17}$ Cardiac rehabilitation programs 
are now increasingly provided in community settings and have developed to accommodate other functions, such as assessment of individual physical, psychological, and social needs, and provision of information on various issues, including lifestyle recommendations and the use, benefit, and harms of medicines. ${ }^{11,18,19}$ This typically involves multidisciplinary input from health professionals, including nurses, physiotherapists, occupational therapists, dietitians, pharmacists, and social workers. As such, cardiac rehabilitation is defined by the World Health Organization as being:

"... the sum of activities required to influence favorably the underlying cause of the disease as well as the best possible, physical, mental and social conditions, so that they (people) may, by their own efforts preserve or resume when lost, as normal a place as possible in the community. Rehabilitation cannot be regarded as an isolated form or stage of therapy but must be integrated within secondary prevention services of which it forms only one facet". ${ }^{12}$

Cardiac rehabilitation has been shown to benefit patients following a myocardial infarction, as well as before and after coronary artery bypass graft surgery. ${ }^{18,20}$ Benefits have been shown in patients with stable angina and heart failure, as well as for patients with a variety of other CVD-related manifestations. ${ }^{18,20-22}$ Indeed, improved and increasingly available surgical interventions, particularly percutaneous techniques, have resulted in increasing numbers of patients who can benefit from cardiac rehabilitation. ${ }^{20,22}$ Particular benefits that have been shown by systematic reviews include reductions in mortality and morbidity, improved healthrelated quality of life, and improvements in a variety of physical parameters, including exercise tolerance, blood pressure, and blood lipid profiles. ${ }^{22}$

However, a significant proportion of eligible patients fail to receive cardiac rehabilitation, including those ineligible for thrombolysis, socially deprived patients, women, ethnic minorities, and the elderly. ${ }^{20,22,23}$ Indeed, it was reported in 2006 that in the UK, for example, less than $30 \%$ of patients eligible for cardiac rehabilitation were actually enrolled, and the evidence does not suggest that this picture has substantially improved since. ${ }^{22,23}$ Moreover, recent reports indicate that cardiac rehabilitation service provision in the UK and other countries continues to remain patchy and of variable quality. ${ }^{14,22,24-27}$ Subsequently, improving the quantity and quality of cardiac rehabilitation provision has become a priority in national health policies. ${ }^{28}$

In relation to prevention of $\mathrm{CVD}$, discourses about risk in relation to public health have become an increasingly important feature of contemporary society that has transformed the way disease is defined and how health services are organized and delivered. The emphasis has increasingly moved from treatment to prevention, and from sickness to health. ${ }^{29,30}$ The subsequent impact that this has had on individuals has increased to the point where everyone is expected to take responsibility for care of themselves. ${ }^{30}$ Health policies and educational programs have emphasized personal responsibility, in which choosing a healthy lifestyle is promoted as a rational response to awareness of health risks. ${ }^{3,31}$

Studies of some health promotion and educational programs to prevent CVD have reported significant reductions in the rate of deaths attributable to CVD or 10-year CVD risk. ${ }^{1,32}$ A recent systematic review found that community CVD prevention programs appeared to have achieved favorable changes in overall CVD risk, and found no evidence for rejecting such programs as a beneficial means of CVD prevention. ${ }^{32}$ However, various factors make evaluation of health promotion programs problematic. These include limitations in the study designs used to measure the effects of programs, unrealistic expectations about how quickly the programs may result in sustained changes, and whether lifestyle changes can be directly attributed to particular programs., Nevertheless, whether directly attributable to educational programs or not, the epidemiological evidence suggests that $45 \%-75 \%$ of the recent reduction in CVD deaths in developed countries is due to the reduction in smoking prevalence and dietary modification leading to reduced salt and saturated fat intake, amongst other risk factors. ${ }^{1}$

In short, there is substantial evidence indicating that cardiac rehabilitation is a beneficial intervention in the secondary prevention of CVD, and evidence that educational programs to prevent CVD may achieve favorable reductions in CVD deaths and overall CVD risk. However, the success of cardiac rehabilitation and educational programs is critically dependent on how people perceive their risk of CVD, their perspectives on attending cardiac rehabilitation programs, and their perspectives on taking CVD-related medicines and modifying their lifestyles. The discussion now turns to consider each of these issues in more depth.

\section{Public perceptions of CVD risk}

A key concept in the literature about lay perspectives on the risks of CVD is that of coronary candidacy or the "kind of person who gets heart trouble", as proposed by Davison et al. ${ }^{33-35}$ Based on extensive fieldwork, they argued that people have a coherent approach to assessing 
the risk of coronary heart disease and the likelihood of it happening. ${ }^{33-35}$ They noted that their study population had a significant knowledge of the modifiable risk factors for coronary heart disease, not least as a result of a recent high profile coronary heart disease prevention campaign. This had been incorporated into pre-existing ideas about how, why, and when coronary heart disease might occur. Such theories concerning how the preventability or inevitability of ill health are refined over time were termed "lay epidemiology". They argued that "official" messages about coronary heart disease are incorporated within lay knowledge to form a framework, termed "coronary candidacy", which may be used to assess the risks of coronary heart disease in everyday life, and explain why some people are susceptible to coronary heart disease whilst others are not. This was observed to be happening in four ways, ie, assessing personal risk of coronary heart disease, assessing other people's risk, explaining personal coronary heart disease-related illness, and explaining other people's coronary heart disease-related illness or death.

Individuals perceived to be at risk of coronary heart disease may be identified in three ways, ie, appearance (eg, overweight, unfit, red-faced individuals may be considered to be candidates), social context (eg, people with a family history of coronary heart disease and people in stressful or sedentary jobs), and personal information (eg, people who smoke, eat a high-fat diet, drink a lot of alcohol, or who are "worriers"). ${ }^{33}$ However, built into this is the recognition that candidacy only increases the risk, and is not guaranteed to result in coronary heart disease; some individuals who are not identified as candidates suffer coronary heart disease whilst some obvious candidates do not. These two types of person were termed the "Uncle Norman" figures, who enjoys considerable longevity despite engaging in risky behavior and "The last person you'd expect to have to have a coronary", who avoids such risky behavior, but still succumbs to coronary heart disease. This is explained as a matter of chance, often expressed as bad luck, fate, or destiny. Davison et al proposed that this becomes an integral component of the coronary candidacy framework, and may act as a "barrier to the aims of health education". 33

Emslie et al argued that "the kind of person who gets heart trouble" may be better described as "the kind of person who has a heart attack" because their study respondents focused almost entirely on myocardial infarction rather than other manifestations of CVD. ${ }^{36}$ Death from a myocardial infarction may be seen as a "good way to go", because this is presumed to be quick rather than a slow painful death, which may undermine motivation to modify lifestyle risk factors. ${ }^{37}$ They also argued that age has a significant bearing on coronary candidacy because younger (than around retirement age) people suffering a myocardial infarction tended to be seen as "the last person", whilst coronary candidacy was often not applied to elderly people who died of CVD because "old age" tended to be perceived as the cause. Furthermore, they argued that the coronary candidacy framework is generally only applied to men, and women are generally absent from this system. They noted that their respondents only talked about women with CVD when specifically asked and would typically refer to long-term CVD-related morbidity, rather than using the dramatic mortality-related language typically applied to men. Other studies support the finding that CVD is often perceived as being a man's disease. For example, Ruston and Clayton found that, despite the presence of known risk factors, their women participants did not tend to view themselves as being at risk unless they adopted a "man's way of life". 38

Studies have also looked at how factors such as family history of CVD, ethnicity, stress and hypercholesterolemia, affect people's perceived risk. These study populations typically also had significant knowledge of modifiable risk factors for CVD, which was likewise incorporated within lay epidemiology regarding their own risk. Perceptions of a family history of CVD were found to depend on gender, social class, knowledge of the health of family members, and the number, age, and closeness of relatives with CVD. ${ }^{39,40}$ Even when CVD is known to run in the family, or is a "family weakness", people may still not necessarily perceive themselves to be at risk. ${ }^{39}$ Farooqi et al found that whilst most of their "South Asian" participants were generally aware that a poor diet and lack of exercise are risk factors, some did not seem to be aware that smoking is a risk factor. ${ }^{41}$ Stress was commonly perceived to be a risk factor, including stress related to immigrant status and racial disadvantage. Angus et al similarly found that stress was commonly perceived to be a CVD risk factor. ${ }^{42}$ Studies of people with hypercholesterolemia have found that most people seem to view themselves as being at increased risk of CVD. ${ }^{43-46}$ However, they may find the diagnosis hard to understand and accept if they do not feel unwell. ${ }^{47,48}$ As a result, people may be resistant to lifestyle changes, or not take medicines to reduce cholesterol, such as statins. ${ }^{48,49}$ In short, studies show that people tend to have significant knowledge of the modifiable risk factors for CVD, but this does not necessarily lead to action to reduce risk. 


\section{Patient perspectives on cardiac rehabilitation programs}

Studies that have explored CVD patient perspectives on attending cardiac rehabilitation programs have tended to report that those who do attend perceive cardiac rehabilitation to have been beneficial. Clark et al found that cardiac rehabilitation patients often reported increased trust in their bodies, greater knowledge of their physical limits, and a heightened sense of fitness..$^{50,51}$ They noted that patients benefited from group camaraderie and the opportunity to compare their progress with that of others, as has been found in other studies..$^{52,53}$ Patients may tend to view cardiac rehabilitation as being predominantly about exercise, ${ }^{50,54}$ but other components of cardiac rehabilitation perceived as important by patients include advice, reassurance, and psychological support. ${ }^{55-57}$

However, a number of barriers to patients attending cardiac rehabilitation have been found, of which transport difficulties are a commonly cited barrier. ${ }^{54,57-62}$ Several studies have reported that patients may feel embarrassed about exercising in public, ${ }^{50,57,59}$ although this may lessen through attendance at cardiac rehabilitation. ${ }^{50}$ Some patients dislike group-based formats and prefer home-based cardiac rehabilitation. ${ }^{53}$ Patients' understanding of the cause of their heart attack was also cited as a potential barrier to attendance at cardiac rehabilitation. ${ }^{57,59}$

Additional issues affecting attendance at cardiac rehabilitation include limited resources restricting cardiac rehabilitation service capacity ${ }^{57,62}$ or quality. ${ }^{55,61}$ Tod et al found waiting lists of up to 12 months in some cases, and that patients were often unable to access information about the availability of cardiac rehabilitation, especially those patients who did not speak English or who used sign language. ${ }^{57}$ Many studies noted low attendance at cardiac rehabilitation among women and the elderly. McSweeney and Crane, for example, found that nearly half of the women in their study had not been offered cardiac rehabilitation, and just over a quarter had actually attended ${ }^{60}$ Several studies have noted that family responsibilities were a particular barrier to women attending cardiac rehabilitation..$^{54,57,58,60}$ Overall, studies of patient perspectives on cardiac rehabilitation support the evidence outlined above of attendance at cardiac rehabilitation being beneficial and provide valuable insights into why attendance generally remains low.

\section{Patient perspectives on taking prescribed medicines}

Numerous quantitative studies have found that a significant proportion of CVD patients do not continue to take their CVD-related medicines. ${ }^{16,63-72}$ This proportion varies between studies and between individual medicines, which may be partly explained by the variety of techniques used to measure compliance. ${ }^{68}$ Shah et al, for example, found that at six months after discharge from hospital, $91 \%$ of patients still took a beta-blocker, $85 \%$ of patients still took an angiotensin-converting enzyme inhibitor, and $94 \%$ of patients still took a statin. ${ }^{16}$ However, at three years after discharge from hospital, only $46 \%$ of patients were still taking a beta-blocker, whilst only $36 \%$ of patients were still taking an angiotensin-converting enzyme inhibitor and only $42 \%$ of patients were still taking a statin. ${ }^{16}$ In contrast, a study of cardiac rehabilitation patients between three months and two years after a heart attack found that all the patients reported that they took their medication..$^{73}$ The authors seem to have doubted the authenticity of this finding on the basis that subjects may have reported desirable behavior rather than actual behavior, given the finding of noncompliance in so many previous studies.

The findings of the few qualitative studies that have explored the perspectives of CVD patients on taking CVDrelated medicines are equivocal. Some studies have reported that patients did appear to be taking their medicines as prescribed ${ }^{74-76}$ whilst other studies found that some patients had stopped taking some or all their medicines. ${ }^{77-80}$ Other studies reported a tendency towards taking medicines, but did not account for the views of patients who deviated from this tendency, by reporting that most of the patients seemed to be taking their medicines ${ }^{81}$ or used phrases such as "good adherence was generally found". 82

The most common reasons why patients stopped taking their medicines include fear of dependency, dislike of medicine, and experience of side effects. ${ }^{78-80,83}$ In contrast, MacDermott found that stable angina patients took their medicines despite experiencing side effects. ${ }^{74}$ Other studies have reported patient concerns about medicines without relating this to compliance. This includes concern about side effects, ${ }^{81,84-87}$ as well as patients perceiving medicines to be an "intrusion on their daily life" and concern about having to take them for the rest of their lives ${ }^{84}$ or that some patients disliked taking medicines. ${ }^{83,84,87}$

Studies have reported that some patients view medicines in terms of preventing another heart attack, ${ }^{74,82,84}$ delaying progression of $\mathrm{CVD},{ }^{88}$ or as an aid to recovery. ${ }^{85}$ However, studies have also found that either some or many patients did not know what medicines they were taking or how the medicines work. ${ }^{76,78,79,81,87,88}$ In short, these studies point to there being considerable disquiet among patients about 
taking medicines prescribed for CVD, which in some instances may lead to them not continuing to take some or all of their medicines. However, no clear picture has emerged from the literature as to the overall likelihood of patients continuing to take CVD-related medicines.

\section{Patient perspectives on lifestyle modification recommendations}

In relation to patient perspectives on lifestyle modification, two broad themes seem evident from the literature. Firstly, some patients, but not all, make and maintain some lifestyle changes but not necessarily all of the changes recommended. ${ }^{76,80,85,87,89-93}$ Secondly, patients often experience difficulty in making and maintaining lifestyle changes. ${ }^{85,94-100}$ The literature also provides valuable insights into the reasons why people make lifestyle changes and how they respond to information about lifestyle modification provided by cardiac rehabilitation programs and health promotion programs.

Numerous studies have reported that patients may perceive that lifestyle change is needed to prevent further myocardial infarctions..$^{88,89,92,95,96,101-103}$ White et al found that the aspects of lifestyle that cardiac rehabilitation patients modified and maintained tended to be those that were perceived to have been likely causes of their CVD. ${ }^{75}$ Conversely, aspects of lifestyle that patients did not seem to perceive as likely causes did not tend to have been changed, or were initially changed but did not tend to have been maintained. Other studies have reported that patients appeared to view lifestyle changes in terms of leading to improvements in their health or getting "back to normal" ${ }^{76,85,93,102}$

Many studies have drawn attention to the difficulties that patients often have in making and maintaining lifestyle changes. LaCharity found that patients reduced the difficulty of maintaining dietary changes by making "planned exceptions", ${ }^{97}$ whilst Kerr and Fothergill-Bourbonnais found that some older patients used "cheating" as a way of regaining control over their lives. ${ }^{104}$ LaCharity also found that older women experienced difficulty because of food cravings and a lack of interest in preparing meals. ${ }^{96}$ Gambling found it common for patients to become resentful of the restrictions on their lifestyle and only temporarily give them up. ${ }^{91}$ Studies have found that patients may find maintaining regular physical exercise difficult because of a dislike of exercise, poor weather, or experiencing symptoms, ${ }^{97}$ that patients perceive the recommendations to be unrealistic and "asking too much", ${ }^{91}$ or lack of access to facilities to exercise. ${ }^{97}$ In other instances, patients perceive there to be too many changes to make at once, ${ }^{91,95}$ and so they may overcompensate in one area of lifestyle modification to make up for not modifying another. ${ }^{91}$

Some studies noted gender differences in the lifestyle modifications made, for example, that men tended to see lifestyle modification as a joint venture with their partner, ${ }^{102,105}$ whilst women tended to make lifestyle modifications independently and were reluctant to make changes that might disrupt the whole family routine. ${ }^{91,102}$ Studies have found that women tended to view exercise primarily in terms of losing weight and keeping fit and mobile rather than in terms of CVD prevention. ${ }^{38,106}$ It has also been found that women tended to perceive that the activity inherent in their domestic lives provided moderate physical activity, which may be considered to be best because overexercising may be considered potentially harmful. ${ }^{106,107}$

Research has also pointed to insufficient information being given to patients about lifestyle modification ${ }^{77,91,100,108}$ or found that they have insufficient knowledge to be able to make lifestyle changes. ${ }^{81,85,95}$ For example, studies have found that patients were aware that they needed to reduce their fat intake, but they were often not sure about exactly what they should be eating. ${ }^{77,85,91}$ Inadequate provision of appropriate information may be a particular problem for certain groups of patients, such as those from ethnic minority backgrounds. ${ }^{106,108,109}$ Gambling pointed out that a particular issue for patients was that information was generalized, such that "everyone received the same instructions" rather than being tailored to their individual needs. Subsequently, patients decided for themselves what information was relevant to them. ${ }^{91}$

Importantly, these studies suggest that in many instances people do not appear to view lifestyle risk reduction in terms of a series of targets, which may require lifestyle modification to achieve, as is advocated in standards and guidance., ${ }^{2,4}$ Neither it seems do people appear to accept uncritically generalized advice about lifestyle changes that they are given on cardiac rehabilitation programs or via health promotion campaigns. Rather, people seem to relate information about lifestyle risk factor reduction to their own circumstances, which highlights the tension between approaches to CVD risk reduction in the population at large and individual perspectives. ${ }^{33-35,91}$

This tension has largely arisen from the application of population-based estimates of risk to individual people. ${ }^{33-35}$ The difficulty with these approaches is that assessments of any individual person's risk, despite the sophistication of the technique, ${ }^{2,10}$ remain based on population data. As such, 
they cannot predict with certainty which individuals will be affected by CVD, or which patients with CVD will experience further CVD-related events. ${ }^{31}$ Indeed, a consequence of population-based approaches is the situation, which has been termed the "prevention paradox", ${ }^{7}$ whereby CVD-related mortality substantially falls in the population, but many people who reduce their lifestyle risk factors would not have developed CVD anyway. An uncomfortable implication of this is that people may be unlikely to modify their lifestyles if they are told that, statistically speaking, they are unlikely to benefit on an individual basis. ${ }^{33-35}$ To a lesser extent, this also applies to approaches that target high-risk individuals, in that the approach itself may be effective in reducing CVD-related morbidity and mortality in the population, but not all of the people who change their lifestyles would have been affected by CVD or experienced further CVD-related events had they not done so.

Nevertheless, in the pursuit of CVD risk reduction in the population, considerable effort over the last several decades has been put into health promotion and health education strategies and activities, including cardiac rehabilitation programs. In these, a strong emphasis has been placed on heightening peoples' awareness of their risk of CVD and on their personal responsibility for reducing lifestyle risk factors. $^{31,33,34}$ This makes the all-important step of personalizing risk such that it moves from the population as a whole to the individual, which does not avoid the problems of the prevention paradox. Despite this, as these studies suggest, there appears to be a complex interplay between factors that influence peoples' response to educational programs, and there is no clear link between adequate provision of information, peoples' understanding, and the likelihood of them making or maintaining lifestyle changes, or continuing to take medicines. However, there has since been increased interest in the wider social factors that shape the landscape within which people make lifestyle choices. This has resulted in new health policies, guidance, and patient approaches to reduce further the burden of CVD, which this discussion now turns to.

\section{Update on new developments and patient approaches}

A number of important public health guidance documents have recently been published, which build on the World Health Organization guidance on CVD prevention. ${ }^{2}$ These include the UK National Institute of Health and Clinical Excellence guidance on prevention of CVD at the population level, ${ }^{1}$ the UK government's public health White Paper, ${ }^{110}$ and a position paper on secondary prevention of CVD through cardiac rehabilitation from the European Association of Cardiovascular Prevention and Rehabilitation. ${ }^{11}$

These documents mark an important shift away from prevention (both primary and secondary) of CVD being viewed solely as a matter of individual choice, and instead recognize the wider societal issues that influence, and sometimes constrain, the lifestyle choices people make. In particular, the National Institute of Health and Clinical Excellence guidance on CVD prevention at a population level makes a series of recommendations on a range of such issues, including the high salt and fat (saturated and trans) content of processed foods, the lack of clarity in food product labeling, the availability of healthy food choices relative to takeaway food outlets and other outlets, marketing and promotion of foods that are aimed at children, other commercial interests acting as barriers to CVD prevention, and increasing physically active travel opportunities. ${ }^{1}$ These recommendations are intended to be implemented in conjunction with other initiatives aimed at reducing specific risk factors, such as tobacco control measures, and those aimed at encouraging individual people to make healthy lifestyle choices. Crucially, the guidance highlights that many of the modifiable risk factors for CVD are also risk factors for other noncommunicable diseases.

In relation to cardiac rehabilitation services, there has been a renewed emphasis on improving the provision and the quality of cardiac rehabilitation programs provided, as well as widening access and increasing attendance at cardiac rehabilitation. This supports cardiac rehabilitation service standards documents, such as the British Association for Cardiac Rehabilitation standards and core components for cardiac rehabilitation services, and the American Association of Cardiovascular and Pulmonary Rehabilitation guidance. ${ }^{19}$ It is increasingly being recognized that, in order to widen access to cardiac rehabilitation, there needs to be a range of effective alternatives to the traditional model of hospital-based cardiac rehabilitation programs. A recent systematic review of home-based versus center-based cardiac rehabilitation found that home-based cardiac rehabilitation was as effective as center-based cardiac rehabilitation in reducing mortality and cardiac events, and improving physical parameters, such as exercise capacity, blood pressure, and cholesterol. ${ }^{111}$ In addition, no differences in costs or patient adherence were found between home-based or center-based cardiac rehabilitation. Other means of increasing access have utilized technological innovations such as "Telehealth", which involves patients communicating with cardiac rehabilitation service providers by telephone, Internet, and video conferencing. ${ }^{12}$ This has also been shown to reduce 
mortality and improve CVD risk factors such as blood pressure, cholesterol, and smoking prevalence.

\section{Future developments}

Reducing further the burden of CVD in the global population remains a huge and complex challenge, but opportunities for future developments seem evident in innovative technological solutions to widening access to cardiac rehabilitation services and educational programs, such as those discussed above. Similarly, reorganization of public health activities, such as is proposed in the UK government's recent White Paper, ${ }^{110}$ where closer integration between community services and public health initiatives may result in effective local approaches to CVD prevention being adopted. However, as Davison et al argued in 1991 in relation to overcoming the prevention paradox:

"It will only be with the socialization of health, when it is seen as a collective and not an individual phenomenon, that the problems of the prevention paradox will be overcome", 33

As such, the recent shift in health policy marks a welcome step in this direction by recognizing the complexity of societal influences on people's lifestyle choices, rather than individual failures in preventing CVD. Future developments in this direction may offer the most substantial and sustainable means of creating awareness of, preventing, and managing CVD.

\section{Conclusion}

Current approaches to creating awareness of, preventing, and managing CVD include primary prevention strategies (eg, public health and educational programs) to reduce risk factors in the whole population and those aimed at people at high risk of developing manifestations of CVD, and secondary prevention strategies (eg, cardiac rehabilitation services) aimed at people who already exhibit such manifestations. Evidence-based guidance recommends that such strategies should include CVD risk assessment and modification of lifestyle risk factors. People at high risk of CVD should also be prescribed appropriate medication. There is substantial evidence indicating that cardiac rehabilitation is a beneficial intervention in the secondary prevention of CVD, and studies of patient perspectives on cardiac rehabilitation suggest that patients who attend usually consider it to be beneficial. Despite this, a significant proportion of eligible patients fail to receive cardiac rehabilitation, and numerous barriers to attendance remain, particularly because cardiac rehabilitation service provision continues to be patchy and of variable quality.

There is evidence that educational programs to prevent CVD may achieve favorable reductions in mortality and overall CVD risk. However, whilst people tend to have significant knowledge of the modifiable risk factors for CVD, this does not necessarily lead to action to reduce risk, because lay epidemiology appears to play a significant role in sophisticated determinations of CVD causation, amongst other factors. Some patients, but not all, make and maintain some lifestyle changes, but not necessarily all of the changes recommended, because they may only change aspects of their lifestyle that are perceived to have been likely causes of their CVD. Many patients also experience difficulty in making and maintaining lifestyle changes. There appears to be considerable disquiet among patients about taking medicines prescribed for CVD, particularly concerning side effects, which in some instances may affect medicine-taking choices.

New developments and patient approaches mark an important shift away from prevention of CVD being viewed solely as a matter of individual choice, and instead recognize the wider societal issues that influence the lifestyle choices people make. Recent developments in increasing attendance and widening access to cardiac rehabilitation have involved home-based and technological innovations as alternatives to the traditional model of hospital-based cardiac rehabilitation programs. Effective future approaches to creating awareness of, preventing, and managing CVD are likely to build on these developments and offer even greater choice in accessing preventative services.

\section{Disclosure}

The author reports no conflict of interest in this work.

\section{References}

1. National Institute of Health and Clinical Excellence. Prevention of Cardiovascular Disease at Population Level. London, UK: National Institute of Health and Clinical Excellence; 2010.

2. World Health Organization. Prevention of Cardiovascular Disease. Guidelines for Assessment and Management of Cardiovascular Risk. Geneva, Switzerland: World Health Organization; 2007.

3. Department of Health. Building on the Best. Choice, Responsiveness and Equity in the NHS. London, UK: Department of Health; 2003.

4. National Institute of Health and Clinical Excellence. Secondary Prevention in Primary and Secondary Care for Patients Following a Myocardial Infarction. London, UK: National Institute of Health and Clinical Excellence; 2007.

5. Artinian N, Fletcher G, Mozaffarian D, et al; on behalf of the American Heart Association Prevention Committee of the Council on Cardiovascular Nursing. Interventions to promote physical activity and dietary lifestyle changes for cardiovascular risk factor reduction in adults: A scientific statement from the American Heart Association. Circulation. 2010;122:406-441. 
6. Rayner M, Allender S, Scarborough P; British Heart Foundation Health Promotion Research Group. Cardiovascular disease in Europe. Eur J Cardiovasc Prev Rehabil. 2009;16 Suppl 2:S43- S47.

7. Rose G. Sick individuals and sick populations. Int J Epidemiol. 1985; $14: 32-38$.

8. Jackson R, Lynch J, Harper S. Preventing coronary heart disease. Does Rose's population prevention axiom still apply in the 21 st century? BMJ. 2006;332:617-618.

9. Manuel D, Lim J, Tanuseputro P, et al. Revisiting Rose: Strategies for reducing coronary heart disease. BMJ. 2006;332:659-662.

10. Joint British Societies. JBS 2: Joint British Societies' guidelines on prevention of cardiovascular disease in clinical practice. Heart. 2005; 91 Suppl V:1-52.

11. Piepoli M, Corra U, Benzer W, et al. Secondary prevention through cardiac rehabilitation: From knowledge to implementation. A position paper from the Cardiac Rehabilitation Section of the European Association of Cardiovascular Prevention and Rehabilitation. Eur J Cardiovasc Prev Rehabil. 2010;17:1-17.

12. World Health Organization. Needs and Action Priorities in Cardiac Rehabilitation and Secondary Prevention in Patients with CHD. Geneva, Switzerland: World Health Organization; 1993.

13. Department of Health. Alcohol advice. 2009. Available from: www. dh.gov.uk/en/Publichealth/Healthimprovement/Alcoholmisuse/ DH_085385. Accessed December 22, 2010.

14. Kotseva K, Wood D, DeBacker G, et al; EUROASPIRE Study Group Cardiovascular prevention guidelines in daily practice: A comparison of EUROASPIRE I, II and III surveys in eight European countries. Lancet. 2009;373:929-940.

15. Lavie C, Thomas R, Squires R, Allison T, Milani R. Exercise training and cardiac rehabilitation in primary and secondary prevention of coronary heart disease. Mayo Clinic Proc. 2009;84:373-383.

16. Shah N, Ting H, Montori V, Wagie A, Roger V. Evidence-based therapy for myocardial infarction: Medication adherence in the community. Circulation. 2007;116(16 Suppl):797.

17. Certo C. History of cardiac rehabilitation. Phys Ther. 1985;65: 1793-1795.

18. Department of Health. National Service Framework for Coronary Heart Disease. London, UK: Department of Health; 2000.

19. British Association of Cardiac Rehabilitation. Standards and Core Components for Cardiac Rehabilitation. London, UK: British Association of Cardiac Rehabilitation; 2007.

20. Williams M, Ades P, Hamm L, Keteyian S. Clinical evidence for a health benefit from cardiac rehabilitation: An update. Am Heart J. 2006;152: 835-841

21. Alter D, Oh P, Chong A. Relationship between cardiac rehabilitation and survival after cardiac hospitalization within a universal health care system. Eur J Cardiovasc Prev Rehabil. 2009;16:102-113.

22. Thompson D, Clark A. Cardiac rehabilitation: Into the future. Heart. 2009;95:1897-1900.

23. Bethell H, Lewin R, Dalal H. Cardiac rehabilitation in the United Kingdom. Heart. 2009;95:271-275.

24. British Heart Foundation. The National Audit of Cardiac Rehabilitation Annual Statistical Report 2010. London, UK: British Heart Foundation; 2010 .

25. National Institute of Health and Clinical Excellence. Cardiac Rehabilitation Service Commissioning Guide. London, UK: National Institute of Health and Clinical Excellence; 2008.

26. Korenfeld Y, Mendoza-Bastidas C, Saavedra L, et al. Current status of cardiac rehabilitation in Latin America and the Caribbean. Am Heart J. 2009; $158: 480-487$.

27. Thomas R, King M, Lui K, Oldridge N, Pina I, Spertus J. AACVPR/ ACC/AHA 2007 Performance measures on cardiac rehabilitation for referral to and delivery of cardiac rehabilitation/secondary prevention services. J Am Coll Cardiol. 2007;50:1401-1435.

28. Department of Health. Building for the Future: The Coronary Heart Disease National Service Framework. Progress Report for 2007. London, UK: Department of Health; 2007.
29. Armstrong D. The rise of surveillance medicine. Sociol Health Illn. 1995; 17:393-404.

30. Petersen A, Lupton D. The New Public Health: Health and Self in the Age of Risk. London, UK: Sage; 1996.

31. Wheatley E. Disciplining bodies at risk: Cardiac rehabilitation and the medicalisation of fitness. Journal of Sport and Social Issues. 2005;29: 198-221.

32. Pennant M, Davenport C, Bayliss S, Greenheld W, Marshall T, Hyde C. Community programs for the prevention of cardiovascular disease: A systematic review. Am J Epidemiol. 2010;172:501-516.

33. Davison C, Davey Smith G, Frankel S. Lay epidemiology and the prevention paradox: The implications of coronary candidacy for health education. Sociol Health Illn. 1991;13:1-19.

34. Davison C, Frankel S, Davey Smith G. The limits of lifestyle: Re-assessing "fatalism" in the popular culture of illness prevention. Soc Sci Med. 1992;34:675-685.

35. Frankel S, Davison C, Davey Smith G. Lay epidemiology and the rationality of responses to health education. Br J Gen Pract. 1991;41: 428-430.

36. Emslie C, Hunt K, Watt G. Invisible women? The importance of gender in lay beliefs about heart problems. Sociol Health Illn. 2001;23: 203-233.

37. Emslie C, Hunt K, Watt G. 'I'd rather go with a heart attack than drag on': Lay images of heart disease and the problems they present for primary and secondary prevention. Coronary Health Care. 2001;5: 25-32.

38. Ruston A, Clayton J. Coronary heart disease: Women's assessment of risk - a qualitative study. Health Risk Soc. 2002;4:125-138.

39. Hunt K, Emslie C, Watt G. Lay constructions of a family history of heart disease: Potential for misunderstandings in the clinical encounter. Lancet. 2001;357:1168-1171.

40. Preston R. Ethnography: Studying the fate of health promotion in coronary families. J Adv Nurs. 1997;25:554-561.

41. Farooqi A, Nagra D, Edgar T, Khunti K. Attitudes to lifestyle risk factors for coronary heart disease amongst South Asians in Leicester: A focus group study. Fam Pract. 2000;17:293-297.

42. Angus I, Rukholm E, St Onge R. Habitus, stress and the body: The everyday production of health and cardiovascular risk. Qual Health Res. 2007; 17:1088-1102.

43. Frich J, Ose L, Malterud K, Fugelli P. Perceived vulnerability to heart disease in patients with familial hypercholesterolemia: A qualitative interview study. Ann Fam Med. 2006;4:198-204.

44. Frich J, Malterud K, Fugelli P. How do patients at risk portray candidates for coronary heart disease? A qualitative interview study. Scand J Prim Health Care. 2007;25:112-116.

45. Hollman G, Ek A, Olsson A, Bertero C. The meaning of life among patients with familial hypercholesterolaemia. J Cardiovasc Nurs. 2004;19:243-250.

46. Senior V, Smith J, Michie S, Marteau T. Making sense of risk: An interpretative phenomenological analysis of vulnerability to heart disease. J Health Psychol. 2002;7:157-168.

47. Durack-Bown I, Giral P, d'Ivernois J, et al. Patients and physicians perceptions and experience of hypercholesterolaemia: A qualitative study. Br J Gen Pract. 2003;53:851-857.

48. Troein M, Rastam L, Selander S, Widlund, Uden G. Understanding the unperceivable: Ideas about cholesterol expressed by middle-aged men with recently discovered hypercholesterolaemia. Fam Pract. 1997;14: 376-381.

49. Tolmie E, Lindsay G, Kerr S, Brown M, Ford I, Gaw A. Patients' perspectives on statin therapy for treatment of hypercholesterolaemia: A qualitative study. Eur J Cardiovasc Nurs. 2003;2:141-149.

50. Clark A, Barbour R, White M, MacIntyre P. Promoting participation in cardiac rehabilitation: Patient choices and experiences. J Adv Nurs. 2004;47:5-14

51. Clark A, Whelan H, Barbour R, MacIntyre P. A realist study of the mechanisms of cardiac rehabilitation. J Adv Nurs. 2005;52: 362-371. 
52. Murie J, Ross A, Lough M, Rich D. Exploring post-myocardial infarction patients' perceptions of patient-mediated interventions for the secondary prevention of coronary heart disease (SIGN Guideline 41). Qual Prim Care. 2006;14:77-83.

53. Wingham J, Dalal H, Sweeney K, Evans P. Listening to patients: Choice in cardiac rehabilitation. Eur J Cardiovasc Nurs. 2006;5:289-294.

54. Hird C, Upton C, Chesson R. "Getting back to normal": Patients' understanding of cardiac rehabilitation. Physiotherapy. 2004;90:125-131.

55. Day W, Batten L. Cardiac rehabilitation for women: One size does not fit all. Aust J Adv Nurs. 2006;24:21-26.

56. Higginson R. Why do women attend and continue cardiac rehabilitation? British Journal of Cardiac Nursing. 2006;1:95-102.

57. Tod A, Lacey E, McNeill F. "I'm still waiting ...": Barriers to accessing cardiac rehabilitation services. $J$ Adv Nurs. 2002;40:421-431.

58. Caldwell P, Arthur H, Rideout E. Lives of rural women after myocardial infarction. Can J Nurs Res. 2005;37:54-67.

59. Cooper A, Jackson G, Weinman J, Horne R. A qualitative study investigating patients' beliefs about cardiac rehabilitation. Clin Rehabil. 2005; 19:87-96.

60. McSweeney J, Crane P. An act of courage: Women's decision-making processes regarding outpatient cardiac rehabilitation attendance. Rehabil Nurs. 2001;26:132-140.

61. O'Driscoll J, Shave R, Cushion C. A National Health Service Hospital's cardiac rehabilitation programme: A qualitative analysis of provision. J Clin Nurs. 2007;16:1908-1918.

62. Paquet M, Bolduc N, Xhignesse M, Vanasse A. Re-engineering cardiac rehabilitation programmes: Considering the patient's point of view. J Adv Nurs. 2005;51:567-576.

63. Arif H, Aijaz B, Islam M, Aftab U, Kumar S, Shafqat S. Drug compliance after stroke and myocardial infarction: A comparative study. Neurol India. 2007;55:130-135.

64. Burke L, Dunbar-Jacob J. Adherence to medication, diet and activity recommendations: From assessment to maintenance. $J$ Cardiovasc Nurs. 1995;9:62-79.

65. Choudry N, Winkelmayer W. Medication adherence after myocardial infarction: A long way left to go. J Gen Intern Med. 2008;23: 216-218.

66. Ho P, Magid D, Masoudi F, McClure D, Rumsfeld J. Adherence to cardioprotective medications and mortality among patients with diabetes and ischemic heart disease. BMC Cardiovasc Disord. 2006;6:48.

67. Kopjar B, Sales A, Pineros S, Sun H, Li Y, Hedeen A. Adherence with statin therapy in secondary prevention of coronary heart disease in Veterans Administration male population. Am J Cardiol. 2003;92: 1106-1108.

68. Lee J, Grace K, Foster T, et al. How should we measure medication adherence in clinical trials and practice? Ther Clin Risk Manage. 2007;3: 685-690.

69. Newby L, Allen LaPointe N, Chen A, et al. Long-term adherence to evidence-based secondary prevention therapies in coronary artery disease. Circulation. 2006;113:203-212.

70. Rasmussen J, Chong A, Alter D. Relationship between adherence to evidence-based pharmacotherapy and long-term mortality after acute myocardial infarction. JAMA. 2007;297:177-186.

71. Sud A, Kline Rogers E, Eagle K, et al. Adherence to medications by patients after acute coronary syndromes. Ann Pharmacother. 2005;39: 1792-1797.

72. Ye X, Gross C, Schommer J, Cline R, Peter W. Association between copayment and adherence to statin treatment initiated after coronary heart disease hospitalisation: A longitudinal, retrospective cohort study. Clin Ther. 2007;29:2748-2757.

73. Leong J, Molassiotis, Marsh H. Adherence to health recommendations after a cardiac rehabilitation programme in post-myocardial infarction patients: The role of health beliefs, locus of control and psychological status. Clin Eff Nurs. 2004;8:26-38.

74. MacDermott A. Living with angina pectoris - a phenomenological study. Eur J Cardiovasc Nurs. 2002;1:265-272.
75. White S, Bissell P, Anderson C. A qualitative study of patients' perspectives on cardiac rehabilitation, lifestyle change and taking medicines: Implications for service development. J Health Serv Res Policy. 2010;15 Suppl 2:47-53.

76. Wiles R, Kinmonth A. Patients' understandings of heart attack: Implications for prevention of recurrence. Patient Educ Couns. 2001;44: $161-169$.

77. Crane P. I want to know: Exploring how older women acquire health knowledge after a myocardial infarction. $J$ Women Aging. 2001;13:3-20.

78. Haugbolle L, Sorensen E, Gundersen B, Petersen K, Lorentzen L. Basing pharmacy counselling on the perspective of the angina pectoris patient. Pharm World Sci. 2002;24:71-78.

79. Haugbolle L, Sorensen E, Henriksen H. Medication and illness-related factual knowledge, perceptions and behaviour in angina pectoris patients. Patient Educ Couns. 2002;47:281-289.

80. Tolmie E, Lindsay G, Belcher P. Coronary artery bypass graft operation: Patients' experience of health and well-being over time. Eur J Cardiovasc Nurs. 2006;5:228-236.

81. Karner A, Goransson A, Bergdahl B. Conceptions on treatment and lifestyle in patients with coronary heart disease - a phenomenographic analysis. Patient Educ Couns. 2002;47:137-143.

82. Ononeze V, Murphy A, Byrne M, Bradley C, Macfarlane A. Patients and health professionals' perspectives on the sociocultural influences on secondary cardiac behaviour: A qualitative study of the implications in policy and practice. Fam Pract. 2006;23:587-596.

83. Lehane E, McCarthy G, Collender V, Deasy A. Medication-taking for coronary artery disease - patients' perspectives. Eur J Cardiovasc Nurs. 2008;7:133-139.

84. Attebring M, Herlitz J, Ekman I. Intrusion and confusion - the impact of medication and health professionals after acute myocardial infarction. Eur J Cardiovasc Nurs. 2005;4:153-159.

85. Bergman E, Bertero C. You can do it if you set your mind to it: A qualitative study of patients with coronary artery disease. $J A d v$ Nurs. 2001;36:733-741.

86. Johansson A, Dahlberg K, Ekebergh M. Living with experiences following a myocardial infarction. Eur J Cardiovasc Nurs. 2003;2: 229-236.

87. Roebuck A, Furze G, Thompson D. Health-related quality of life after myocardial infarction: An interview study. $J$ Adv Nurs. 2001;34: 787-794.

88. Treloar C. Developing a multilevel understanding of heart disease: An interview study of MONICA participants in an Australian center. Qual Health Res. 1997;7:468-486.

89. East L, Brown K, Twells C. "Knocking on St Peter's door". A qualitative study of recovery after a heart attack and the experience of cardiac rehabilitation. Prim Health Care Res Dev. 2004;5:202-210.

90. Ford J. Living with a history of heart attacks: A human science investigation. JAdv Nurs. 1989;14:173-179.

91. Gambling T. A qualitative study into the informational needs of coronary heart disease patients. International Journal of Health Promotion and Education. 2003;41:68-76.

92. Jensen B, Petersson K. The illness experience of patients after a first time myocardial infarction. Patient Educ Couns. 2003;51:123-131.

93. Wiles R. Patient's perceptions of their heart attack and recovery: The influence of epidemiological "evidence" and personal experience. Soc Sci Med. 1998;46:1477-1486.

94. Boutin-Foster C. Getting to the heart of social support: A qualitative analysis of the types of instrumental support that are most helpful in motivating cardiac risk factor modification. Heart Lung. 2005;34: 22-29.

95. Condon C, McCarthy G. Lifestyle changes following acute myocardial infarction: Patients perspectives. Eur J Cardiovasc Nurs. 2006;5: $37-44$.

96. LaCharity L. The experiences of postmenopausal women with coronary artery disease. West J Nurs Res. 1997;19:583-607. 
97. LaCharity $\mathrm{L}$. The experiences of younger women with coronary artery disease. J Womens Health Gend Based Med. 1999;8:773-785.

98. Plach S, Stevens P. Midlife women's experiences living with heart disease. Appl Nurs Res. 2001;14:201-209.

99. Sjöström-Strand A, Fridlund B. Stress in women's daily life before and after a myocardial infarction: A qualitative analysis. Scand J Caring Sci. 2007;21:10-17.

100. Thomas D. Women and heart disease: Living with lifestyle changes a pilot study. AACN Clin Issues Crit Care Nurs. 1994;5:21-25.

101. Fleury J, Sedikides C. Wellness motivation in cardiac rehabilitation: The role of self-knowledge in cardiovascular risk modification. Res Nurs Health. 2007;30:373-384.

102. Johnson J, Morse J. Regaining control: The process of adjustment after myocardial infarction. Heart Lung. 1990;19:126-135.

103. Scherck K. Coping with acute myocardial infarction. Heart Lung. 1992;21:327-334.

104. Kerr E, Fothergill-Bourbonnais F. The recovery mosaic: Older women's lived experiences after a myocardial infarction. Heart Lung. 2002;31:355-367.

105. Stewart M, Davidson K, Meade D, Hirth A, Makrides L. Myocardial infarction: Survivors' and spouses' stress, coping and support. $J A d v$ Nurs. 2000;31:1351-1360.
106. Sriskantharajah J, Kai J. Promoting physical activity among South Asian women with coronary heart disease and diabetes: What might help? Fam Pract. 2007;24:71-76.

107. Clayton J, Ruston A. Exercising for a healthy heart: A qualitative study of women's beliefs. Health Educ J. 2003;62:29-40.

108. Webster R, Thompson D, Mayou R. The experiences and needs of Gujarati Hindu patients and partners in the first month after myocardial infarction. Eur J Cardiovasc Nurs. 2002;1:69-76.

109. King K, LeBlanc P, Sanguins J. Gender-based challenges faced by older Sikh women as immigrants: Recognizing and acting on the risk of coronary artery disease. Can J Nurs Res. 2006;38:16-40.

110. Department of Health. Healthy Lives, Healthy People: Our Strategy for Public Health in England (Cm 7985). London, UK: The Stationary Office; 2010.

111. Dalal H, Zawada A, Jolly K, Moxham T, Taylor R. Home based versus centre based cardiac rehabilitation: Cochrane systematic review and meta-analysis. BMJ. 2010;340:b5631.

112. Neubeck L, Redfern J, Fernandez R, Briffa T, Bauman A, Freedman S. Telehealth interventions for the secondary prevention of coronary heart disease: A systematic review. Eur J Cardiovasc Prev Rehabil. 2009;16:281-289.
Patient Intelligence

\section{Publish your work in this journal}

Patient Intelligence is an international, peer-reviewed, open access journal that characterizes and measures the central role of patient behavior and intention in optimizing healthcare management in all areas of disease and complaint types. An improved understanding of patient intelligence coupled with predictive analysis helps an organization contribute more effectively to achieving better outcomes.

Submit your manuscript here: http://www.dovepress.com/patient-intelligence-journal

\section{Dovepress}

The journal is characterized by the rapid reporting of reviews, original research, methodologies, analytics, modeling, clinical studies and patient surveys across all disease areas. The manuscript management system is completely online and includes a very quick and fair peer-review system. Visit http://www.dovepress.com/ testimonials.php to read real quotes from published authors. 